Supplement of Atmos. Meas. Tech., 13, 5513-5535, 2020

https://doi.org/10.5194/amt-13-5513-2020-supplement

(C) Author(s) 2020. This work is distributed under

the Creative Commons Attribution 4.0 License.

(c) (1)
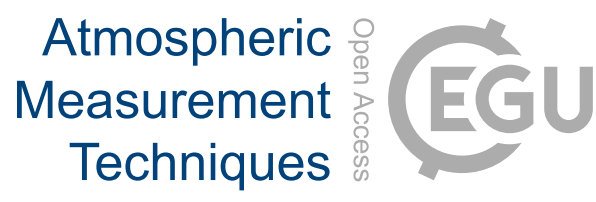

Supplement of

\title{
Satellite validation strategy assessments based on the AROMAT cam- paigns
}

\author{
Alexis Merlaud et al. \\ Correspondence to: Alexis Merlaud (alexism@oma.be)
}

The copyright of individual parts of the supplement might differ from the CC BY 4.0 License. 


\section{Site characteristics}

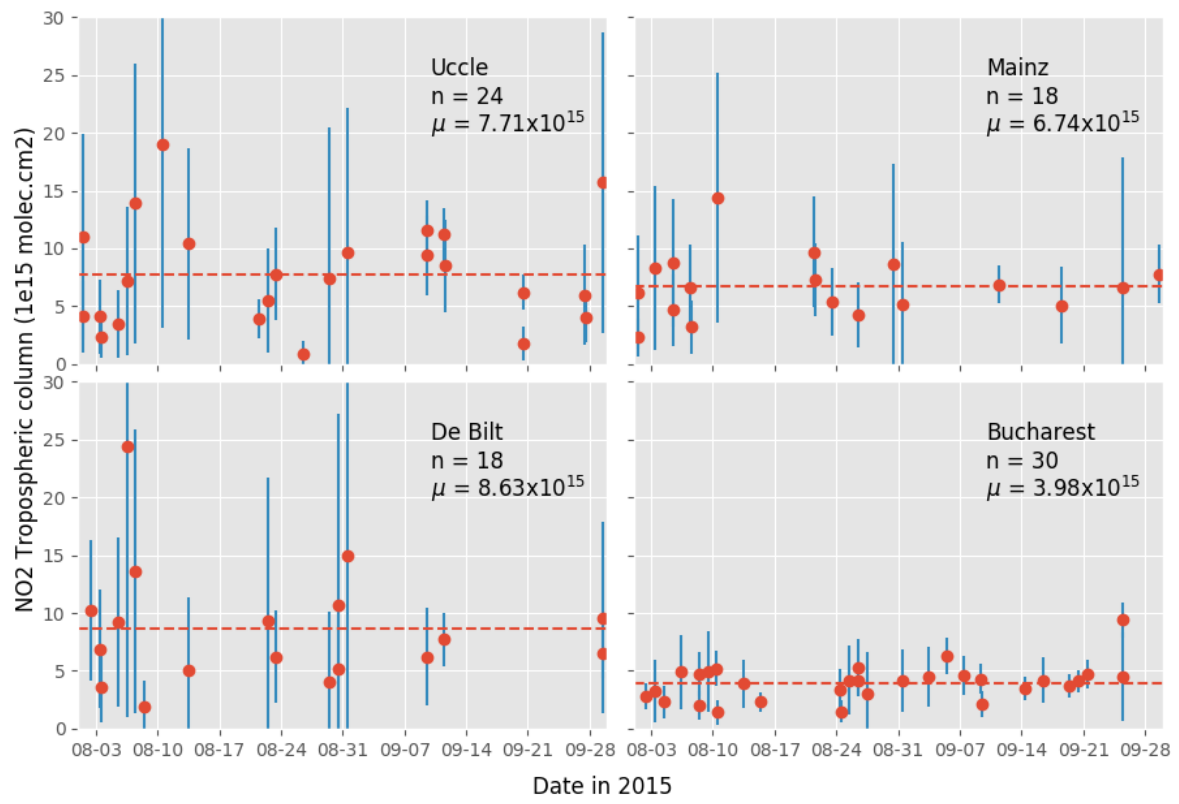

Figure S1. Tropospheric $\mathrm{NO}_{2}$ VCDs for OMI overpasses around four European sites including Bucharest, filtered to remove cloudy scenes and row anomalies (TEMIS $\mathrm{NO}_{2}$ overpass data). The red dashed line indicates the mean $\mathrm{NO}_{2} \mathrm{VCD}$ in the time window. The $\mathrm{NO}_{2}$ column is smaller above Bucharest. This site is less affected by clouds.

Table S1. Main characteristics of the power plants of the Jiu Valley.

\begin{tabular}{ccccc} 
& Craiova II & Islanita & Turceni & Rovinari \\
\hline Latitude $\left({ }^{\circ} \mathrm{N}\right)$ & 44.343 & 44.39 & 44.67 & 44.91 \\
Longitude $\left({ }^{\circ} \mathrm{E}\right)$ & 23.81 & 23.72 & 23.41 & 23.135 \\
Nominal capacity $(\mathrm{MW})$ & 300 & 630 & 1650 & 1320 \\
Smokestack height $(\mathrm{m})$ & 149 & 200 & 280 & 280 \\
\hline
\end{tabular}

\section{Instrument descriptions}

This section presents the instruments which we used in the current study. For a complete list of the instruments operated during the two campaigns, we refer the reader to the technical AROMAT documentation (Merlaud et al., 2016; Constantin et al., 2016).

\subsection{Airborne remote sensing}

\subsubsection{AirMAP}

The AirMAP (Schönhardt et al., 2015; Meier et al., 2017) has been developed at IUP-Bremen. A PhD thesis (Meier, 2018) describes the AirMAP operations and data analysis during the AROMAT campaigns. AirMAP is a pushbroom UV/vis imager 
with a field-of-view of around $51^{\circ}$, leading to a swath width of about the flight altitude. Light is collected by optical fibers from 35 individual viewing directions. The spectrometer is an Acton 300i imaging spectrograph with a focal length of $300 \mathrm{~mm}$, and a f-number of $\mathrm{f} / 3.9$. When measuring primarily $\mathrm{NO}_{2}$, AirMAP records spectra in the range 420-461 nm (AROMAT- 1 settings) or 429-493 nm (AROMAT-2 settings). For the $\mathrm{SO}_{2}$ measurements, the spectral range was set to 303-367 nm. For this UV configuration, the field-of-view decreases to $44^{\circ}$. The spectrometer is temperature stabilized at $35^{\circ} \mathrm{C}$. AirMAP was installed in the FUB Cessna during the AROMAT campaigns.

\subsubsection{SWING}

The SWING payload has been developed at BIRA-IASB. It is a compact whiskbroom UV/vis imager. SWING was upgraded between AROMAT-1 and AROMAT-2. Merlaud et al. (2018) describes the instrument used in AROMAT-1. For AROMAT2, the instrument capabilities in the UV were improved, which enabled to simultaneously measure $\mathrm{SO}_{2}$ and $\mathrm{NO}_{2}$. Light is collected by a scanning mirror driven by a micocontroller. The spectrometer is an Avantes spectrometer (ULS-2048XL) with a focal length of $75 \mathrm{~mm}$, which covers the spectral range of $280-550 \mathrm{~nm}$. The field-of-view of the instrument is tunable but can reach $100^{\circ}$. The instantaneous field-of-view is $5^{\circ}$. The SWING instrument is $12 \mathrm{~cm} \mathrm{x} 8 \mathrm{~cm} \mathrm{x} 33 \mathrm{~cm}$ large and weight $1.2 \mathrm{~kg}$. SWING was operated from the UGAL UAV during AROMAT-1 and from the FUB Cessna during AROMAT-2.

\subsubsection{ULM-DOAS}

The ULM-DOAS payload Constantin et al. (2017) is based on an ULS-2048XL Avantes spectrometer with a focal length of $75 \mathrm{~mm}$, which covers the spectral range of $280-550 \mathrm{~nm}$. A piece of wood under the aircraft wing holds the telescope, which has a $1.2^{\circ}$ field-of-view in the nadir direction. Light is sent from this input optics to the spectrometer by an optical fiber of 400 $\mu \mathrm{m}$. A laptop controls the acquisition and stores the spectra as well as the georeferencing data of a GPS antenna. The entire set-up is powered by the $12 \mathrm{~V}$ of the aircraft through an inverter. The ULM-DOAS measured $\mathrm{NO}_{2}$ and $\mathrm{SO}_{2}$ from the UGAL ultralight aircraft above the Jiu Valley during the AROMAT-2 campaign.

\subsubsection{IUP-Bremen nadir-only DOAS}

A nadir-only DOAS system was operated alongside AirMAP during AROMAT-2. The spectrometer is an Avantes ULS $2048 \times 64$, it has a focal length of $75 \mathrm{~mm}$ and covers the spectral range $287-551 \mathrm{~nm}$ at a spectral resolution of $0.8 \mathrm{~nm}$ (FWHM). A round-to-linear bundle of $14100 \mu \mathrm{m}$ thick fibers collects the light, achieving an effective field of view of $8.1^{\circ}$. This leads to an across track footprint of $425 \mathrm{~m}$ at $3 \mathrm{~km}$ a.g.l. During the Bucharest flight for $\mathrm{H}_{2} \mathrm{CO}$, the integration time was set to $30 \mathrm{~s}$ which leads to a pixel length of $1.8 \mathrm{~km}$.

\subsubsection{FUBISS-ASA2}

The airborne spectrometer system FUBISS-ASA2 (Zieger et al., 2007) has been developed at the Institute for Space Sciences at the Free University of Berlin. It simultaneously measures the direct solar irradiance and the aureole radiance in two different solid angles. Light is collected by a sun tracker. Ring shaped apertures shield the direct sunlight and only allow radiation between $4^{\circ}$ and $6^{\circ}$. The spectrometers used for the sun as well as the aureole photometers provide 256 evenly spaced channels from 300 to $1000 \mathrm{~nm}$. During the AROMAT campaigns, the FUBISS-ASA2 was operated from the FUB Cessna and provided aerosol optical depth profiles in the vicinity of Bucharest.

\subsection{Airborne in-situ}

\subsubsection{KNMI $\mathrm{NO}_{2}$ sonde}

The measurement principle of the KNMI $\mathrm{NO}_{2}$-sonde(Sluis et al., 2010) is based upon the chemical reaction between $\mathrm{NO}_{2}$ and luminol, a chemiluminescent reaction that produces a faint blue light. Ambient air is pumped through a teflon pump, and bubbled through the sensing solution. The light that is produced by the reaction is detected by an array of photodiodes that is glued to the reaction chamber. The electric current from the photodiodes is converted into a voltage with a highly sensitive 
operational amplifier, and passed through a filter that removes high frequency fluctuations. During AROMAT-1, the $\mathrm{NO}_{2}$-sonde was mounted on the UGAL UAV and attached to meteorological balloons. During AROMAT-2, the $\mathrm{NO}_{2}$-sonde was installed onboard the INCAS BN-2.

\subsubsection{AS32M CAPS}

The AS32M NO 2 monitor is a commercial instrument manufactured by Environnement S.A. It follows the Cavity Attenuated Phase Shift (CAPS) principle(Kebabian et al., 2005). It measures the $\mathrm{NO}_{2}$ volume mixing ratio using a blue light-emitting diode (LED) as a light source, a near-co focal arrangement of two high reflectivity mirrors in tandem with an enclosed sample cell of 26 centimeter in length and a vacuum phototube detector. The wavelength and spectral band pass of the measurement are defined by the use of an interference filter centered at $450 \pm 10$ nanometer. The monitor is enclosed within a standard 19 inch rack-mounted instrumentation box, weighs 12.5 kilogram, and uses 225 Watts of electrical power including the vacuum pump. The $\mathrm{NO}_{2}$ CAPS was mounted onboard the BN-2 during AROMAT-2.

\subsubsection{PICARRO G2401-mc}

The Picarro G2401-mc is a commercial instrument that simultaneously quantifies the concentrations of water vapor, carbon monoxide, carbon dioxide and methane(Chen et al., 2013). The instrument uses a tunable laser and applies the cavity ring down spectroscopy technique to measure spectral absorption of molecules in an optical cavity. The model G2401-mc is designed for airborne operations and also provides the dry gas mole fractions. The PICARRO G2401-mc was operated from the BN-2 during AROMAT-2.

\subsection{Car-based Mobile-DOAS systems}

\subsubsection{BIRA Double channel Mobile-DOAS}

The BIRA double channel Mobile-DOAS instrument(Merlaud, 2013) is based on a double channel Avantes spectrometer installed on a car. The entry slit is $50 \mu \mathrm{m}$, the focal length $75 \mathrm{~mm}$ and the grating is a $6001 . \mathrm{mm}^{-1}$, blazed at $300 \mathrm{~nm}$. The spectral range is $200-750 \mathrm{~nm}$ with a $1.3 \mathrm{~nm}$ resolution (FWHM). The CCD detector is a Sony2048 linear array with a Deep-UV coating for signal enhancement below $350 \mathrm{~nm}$. An optical head, mounted on the car window, holds the two telescopes achieving a $2.5^{\circ}$ field-of-view with fused silica collimating lenses. One telescope points zenith while the other is directed $30^{\circ}$ above the horizon. Two $400 \mu \mathrm{m}$ chrome plated brass optical fibers connects the telescopes to the spectrometer. The integration time is around 5ms. Each measurement is an average of (typically) 10 seconds of 10 scans accumulations. A GPS antenna is used for georeferencing the measurement, the whole set-up is powered by the car $12 \mathrm{~V}$ through an inverter. While measuring, the instrument is recording spectra continuously and simultaneously from the two directions.

\subsubsection{UGAL and BIRA zenith-only Mobile-DOAS}

The zenith only Mobile DOAS systems used by UGAL and BIRA(Constantin et al., 2013) are based on Avantes spectrometers installed on a car. They have only one zenith channel, the entry slit is $50 \mu \mathrm{m}$, the focal length $75 \mathrm{~mm}$ and the grating is a 1200 $1 . \mathrm{mm}^{-1}$, blazed at $250 \mathrm{~nm}$. The spectral range is $290-550 \mathrm{~nm}$ with a $0.7 \mathrm{~nm}$ resolution (FWHM). The CCD detector is a 2048 linear array Hamamatsu S11155 with pixels of $14 \mu \mathrm{m}$ x $500 \mu \mathrm{m}$. The fiber is attached to the car and points to the zenith through a fused silica collimating lens resulting in a field of view of $2.5^{\circ}$. The integration time is around $150 \mathrm{~ms}$. Each measurement is an average of (typically) 10 seconds of 10 scans accumulations. The system also uses a GPS antenna for georeferencing the measurements and is also powered by an inverter plugged on the car $12 \mathrm{~V}$.

\subsubsection{MPIC Scanning Mobile-DOAS}

Two mobile Max-DOAS instruments were used by MPIC during the AROMAT campaigns: a Mini-MAX-DOAS and a newly developed instrument, the so-called Tube MAX-DOAS. 
The Mini-MAX-DOAS instrument is a commercial instrument produced by Hoffman GMBH, it is described in detail by (Wagner et al., 2010) which also presents its car-based operation. This instrument uses a thermoelectrically cooled USB2000+ Ocean Optics spectrometer. The latter covers the spectral range $320-460 \mathrm{~nm}$ at a spectral resolution of $0.7 \mathrm{~nm}$. Light is collected within a field of view of $1.2^{\circ}$ through a lens of focal length $40 \mathrm{~mm}$. The optics, spectrometer, and controlling electronics is mounted in a sealed-box enclosure. The whole set-up is rotated by a stepper motor.

The Tube MAX-DOAS has been developed at MPIC and is based on an ULS 2048x64 Avantes spectrometer which covers the spectral range 315-474 $\mathrm{nm}$ at a spectral resolution of $0.7 \mathrm{~nm}$ FWHM. This spectrometer uses a $100 \mu \mathrm{m}$ entry slit, a $18001 . \mathrm{mm}^{-1}$ grating, and a Schott BG3 filter to reduce the visible straylight. The spectrometer is installed inside the car and stabilized at $15^{\circ} \mathrm{C}$. It is connected to the telescope unit through a round-to-linear fibre bundle based on 4 monofibers of diameter $200 \mu \mathrm{m}$. The telescope unit consists of a stepper motor inside a plastic tube which rotates the fiber and a $50 \mathrm{~mm}$ lens outside the tube, leading to a field of view of about $0.7^{\circ}$.

\subsection{Ground-based remote sensing}

\subsubsection{INOE RALI lidar}

The Multiwavelength depolarization Raman Lidar RALI (Nicolae et al., 2010; Belegante et al., 2011) measures the Raman backscattering radiation from atmospheric water vapor, nitrogen, and Mie/Rayleigh backscattering radiation from atmospheric molecules and aerosol particles. It emits and receives light at 1064, 532, and $355 \mathrm{~nm}$. The output parameters are the backscatter coefficient, the extinction coefficient, water vapor mixing ratio, and particle depolarization ratio. The altitude of full overlap is around $800 \mathrm{~m}$. Advanced products have been dedicated to aerosol typing (Nicolae et al., 2018), microphysical inversion and aerosol mass concentration retrievals. The system is part of the European Aerosol Research Lidar Network (EARLINET) as an advanced Lidar station. This instrument performed measurements during both of the campaigns only in Magurele at RADO observatory.

\subsubsection{INOE MILI lidar}

The UV depolarization eye-safe Lidar MILI detects Mie/Rayleigh backscattering from atmospheric molecules and aerosol particles. It emits laser pulses at $355 \mathrm{~nm}(20 \mathrm{~mJ})$ and measures the backscattered light in two orthogonal polarization states. The laser pulse duration is $8 \mathrm{~ns}$ (at $355 \mathrm{~nm}$ ), the repetition rate is $20 \mathrm{~Hz}$, and the beam diameter lies between 3 and $5 \mathrm{~mm}$ (FWHM). The dynamic range covers 1-5 km, depending on the atmosphere transmission, with a spatial resolution of $7.5 \mathrm{~m}$. The reception uses a $200 \mathrm{~mm}$ Cassegrain telescope, and the system acquisition is analog and photon counting, with 20 MS.s ${ }^{-1}$ analog sampling rate and $250 \mathrm{MHz}$ photon counting count rate. The altitude of full overlap was around $500 \mathrm{~m}$ during the AROMAT campaigns, it can be aligned to $300 \mathrm{~m}$.

\subsection{3 $\quad \mathrm{SO}_{2}$ camera}

The $\mathrm{SO}_{2}$ camera is an updated version of the Envicam-2 system described in Kern et al. (2015). It uses a Hamamatsu C8484 fast-sampling camera (1344x1024 pixels), a four-position filter wheel, and a UV spectrometer. The filter wheel holds two 10 $\mathrm{nm}$ filters centered at 310 and $325 \mathrm{~nm}$, respectively corresponding to a strong and weak absorption of $\mathrm{SO}_{2}$, a UV broadband view, and a blackened plate for dark-current measurements. A co-aligned spectrometer receives light within a field-of-view of $0.33^{\circ}$ through a $100 \mathrm{~mm}$ diameter lens. During AROMAT-2, we used a $25 \mathrm{~mm}$ lens for the camera, leading to a field of view of $14.3^{\circ} \times 10.9^{\circ}$.

\subsection{ALTIUS $\mathrm{NO}_{2}$ camera}

The $\mathrm{NO}_{2}$ camera is a hyperspectral imager that can take spectral images of a scene at a given wavelength with a spectral resolution better than $1 \mathrm{~nm}$ (Dekemper et al., 2016). This instrument is composed of a telecentric optical system which images a scene with a $6^{\circ} \times 6^{\circ}$ square field of view (FOV) onto a CCD camera. The incoming light is collected and guided by a number of lenses. The passband selection is made by an acousto-optical tunable filter (AOTF). The AOTF principle relies on the acousto- 
optic interaction in a birefringent crystal: photons of a particular energy (wavelength) couple with an acoustic wave traveling in the crystal in such a way that they leave the crystal in a different direction and with a rotated polarization with respect to the incident beam. The undiffracted beam is rejected with a polarizer and a beam block. The acoustic waves are sent into the crystal by a piezo-electric transducer. The needed acoustic power amounts to about $100 \mathrm{~mW}$.

Table S2. Typical air mass factors (AMF), 1- $\sigma$ DOAS fitting errors $\left(\sigma_{S}\right)$, and integration times (Tint) for the $\mathrm{NO}_{2}$ DOAS instruments. See the references in Sect. 2 for details on the AMF calculations of the airborne instruments. We used geometric approximations for the ground-based DOAS instruments, pointing to zenith $(\mathrm{AMF}=1)$ and $22^{\circ}$ above the horizon $(\mathrm{AMF}=2.7)$.

\begin{tabular}{cccc} 
& AMF & $\sigma_{S}\left(\operatorname{molec~} \mathrm{cm}^{-2}\right)$ & Tint \\
\hline AirMAP & 1.5 & $2.2 \times 10^{15}$ & $0.5 \mathrm{~s}$ \\
SWING & 1.5 & $1.8 \times 10^{15}$ & $0.5 \mathrm{~s}$ \\
ULM-DOAS & 1.5 & $8 \times 10^{14}$ & $10 \mathrm{~s}$ \\
IUP-Bremen nadir & 1 & $2 \times 10^{15}$ & $30 \mathrm{~s}$ \\
Tube MAX-DOAS & 2.7 & $2.5 \times 10^{14}$ & $30 \mathrm{~s}$ \\
Mini MAX-DOAS & 2.7 & $1.2 \times 10^{15}$ & $30 \mathrm{~s}$ \\
UGAL Mobile-DOAS & 1 & $4 \times 10^{14}$ & $30 \mathrm{~s}$ \\
BIRA Mobile-DOAS & 1 & $8 \times 10^{14}$ & $30 \mathrm{~s}$ \\
\hline
\end{tabular}

Table S3. Typical air mass factors (AMF), 1- $\sigma$ DOAS fitting errors $\left(\sigma_{S}\right.$ ), and integration times (Tint) for the $\mathrm{SO}_{2}$ DOAS instruments. See the references in Sect. 2 for details on the AMF calculations of the airborne instruments. We used geometric approximations for the ground-based DOAS instruments, pointing to zenith $(\mathrm{AMF}=1)$ and $22^{\circ}$ above the horizon $(\mathrm{AMF}=2.7)$.

\begin{tabular}{cccc} 
& AMF & $\sigma_{S}\left(\mathrm{molec} \mathrm{cm}^{-2}\right)$ & Tint \\
\hline AirMAP & 1 & $1.7 \times 10^{16}$ & $0.5 \mathrm{~s}$ \\
SWING & 1 & $2 \times 10^{16}$ & $0.5 \mathrm{~s}$ \\
ULM-DOAS & 1 & $5 \times 10^{15}$ & $10 \mathrm{~s}$ \\
Tube MAX-DOAS & 2.7 & $1 \times 10^{16}$ & $30 \mathrm{~s}$ \\
Mini MAX-DOAS & 2.7 & $2 \times 10^{16}$ & $30 \mathrm{~s}$ \\
UGAL Mobile-DOAS & 1 & $4 \times 10^{15}$ & $30 \mathrm{~s}$ \\
\hline
\end{tabular}

Table S4. Typical air mass factors (AMF), 1- $\sigma$ DOAS fitting errors $\left(\sigma_{S}\right)$, and integration times (Tint) for the $\mathrm{H}_{2}$ CO DOAS instruments. See the reference in Sect. 2 for details on the AMF calculations of the airborne instrument. We used geometric approximation for the ground-based DOAS instrument pointing to $22^{\circ}$ above the horizon $(\mathrm{AMF}=2.7)$.

\begin{tabular}{cccc} 
& AMF & $\sigma_{S}($ molec cm & \\
& & Tint \\
\hline IUP-Bremen nadir & 1 & $6 \times 10^{15}$ & $30 \mathrm{~s}$ \\
Tube MAX-DOAS & 2.7 & $1.6 \times 10^{15}$ & $30 \mathrm{~s}$ \\
\hline
\end{tabular}




\section{Practical implementations of the campaigns}

Table S5. Measurements table during the AROMAT 2014 campaign. B stands for Bucharest, J for the Jiu Valley.

\begin{tabular}{ccccccccc} 
& $1-9-14$ & $2-9-14$ & $3-9-14$ & $7-9-14$ & $8-9-14$ & $9-9-14$ & $11-9-14$ & $12-9-14$ \\
\hline AirMAP & B & B & - & - & B & B & J & J \\
SWING & - & - & - & - & - & J & J & - \\
NO $_{2}$ sonde & - & - & - & - & J & J & J & J \\
BIRA Mobile-DOAS & B & B & B & J & J & J & J & J \\
UGAL Mobile-DOAS & B & B & B & B & B & J & J & J \\
MPIC Mobile-DOAS & - & B & B & B & B & J & J & J \\
RALI & B & B & - & B & B & B & B & B \\
MILI & B & B & - & - & - & J & J & - \\
\hline
\end{tabular}

Table S6. Measurements during the AROMAT $2 \mathrm{O} 15$ campaign. B stands for Bucharest, J for the Jiu Valley.

\begin{tabular}{ccccccccc} 
& $24-8-15$ & $25-8-15$ & $26-8-15$ & $27-8-15$ & $28-8-15$ & $29-8-15$ & $30-8-15$ & $31-8-15$ \\
\hline AirMAP & - & - & - & - & $\mathrm{J}$ & - & $\mathrm{B}$ & $\mathrm{B}$ \\
SWING & - & - & - & - & $\mathrm{J}$ & - & $\mathrm{B}$ & $\mathrm{B}$ \\
FUBISS & - & - & - & - & - & - & $\mathrm{B}$ & $\mathrm{B}$ \\
ULM-DOAS & $\mathrm{J}$ & $\mathrm{J}$ & $\mathrm{J}$ & $\mathrm{J}$ & - & - & - & - \\
$\mathrm{NO}_{2}$ camera & $\mathrm{J}$ & $\mathrm{J}$ & - & - & - & - & - & - \\
$\mathrm{SO}_{2}$ camera & $\mathrm{J}$ & $\mathrm{J}$ & $\mathrm{J}$ & $\mathrm{J}$ & $\mathrm{J}$ & $\mathrm{J}$ & - & - \\
$\mathrm{NO}_{2}$ Sonde & - & $\mathrm{B}$ & - & $\mathrm{B}$ & $\mathrm{B}$ & - & - & - \\
CAPS & - & $\mathrm{B}$ & - & $\mathrm{B}$ & $\mathrm{B}$ & - & $\mathrm{B}$ & $\mathrm{B}$ \\
PICARRO & - & $\mathrm{B}$ & - & $\mathrm{B}$ & $\mathrm{B}$ & - & $\mathrm{B}$ & $\mathrm{B}$ \\
BIRA Mobile-DOAS & $\mathrm{J}$ & $\mathrm{J}$ & $\mathrm{J}$ & $\mathrm{J}$ & $\mathrm{J}$ & $\mathrm{B}$ & $\mathrm{B}$ & $\mathrm{B}$ \\
MPIC Mobile-DOAS & $\mathrm{J}$ & $\mathrm{J}$ & $\mathrm{J}$ & $\mathrm{J}$ & $\mathrm{J}$ & $\mathrm{B}$ & $\mathrm{B}$ & $\mathrm{B}$ \\
UGAL Mobile-DOAS & - & - & - & $\mathrm{J}$ & $\mathrm{J}$ & $\mathrm{B}$ & $\mathrm{B}$ & $\mathrm{B}$ \\
RALI & $\mathrm{B}$ & $\mathrm{B}$ & $\mathrm{B}$ & $\mathrm{B}$ & $\mathrm{B}$ & $\mathrm{B}$ & $\mathrm{B}$ & $\mathrm{B}$ \\
MILI & $\mathrm{J}$ & $\mathrm{J}$ & $\mathrm{J}$ & $\mathrm{J}$ & $\mathrm{J}$ & $\mathrm{J}$ & - & - \\
\hline
\end{tabular}


This section presents the intercomparisons performed during the AROMAT-2 campaign which are the most relevant for the findings of this study. Meier et al. (2017) and Merlaud et al. (2018) presented other comparisons based on the AROMAT-1 data.
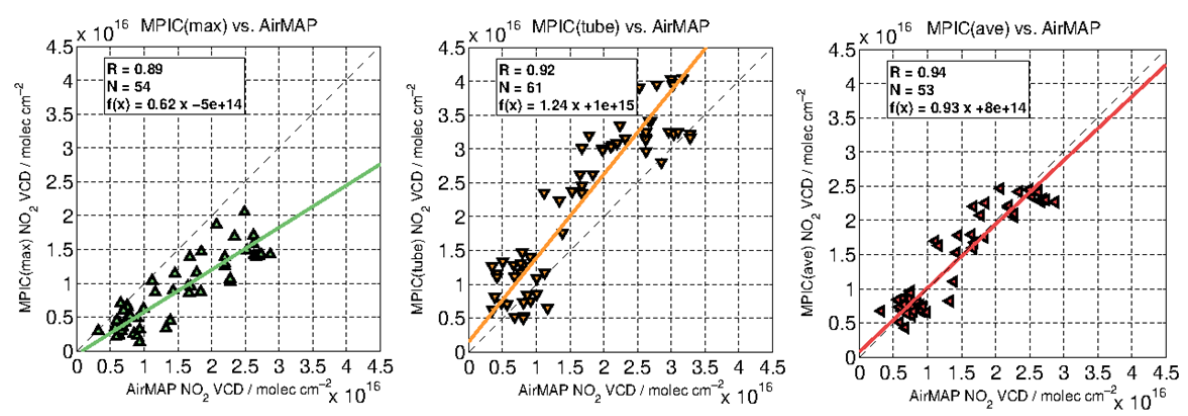

Figure S2. Comparison of AirMAP and MPIC Mobile DOAS $\mathrm{NO}_{2}$ VCDs measurements during the morning flight (07:00-09:30 UTC) on 31 August 2015. The left panel compares AirMAP with the Mini-MAX-DOAS which pointed forward, $22^{\circ}$ above the horizon. The middle panel compares AirMAP with the Tube MAX-DOAS which pointed backward, $22^{\circ}$ above the horizon. The right panel compares AirMAP with the average of the Mini-MAX-DOAS and Tube MAX-DOAS. The maximum time difference between airborne and ground-based data is 45 minutes. 

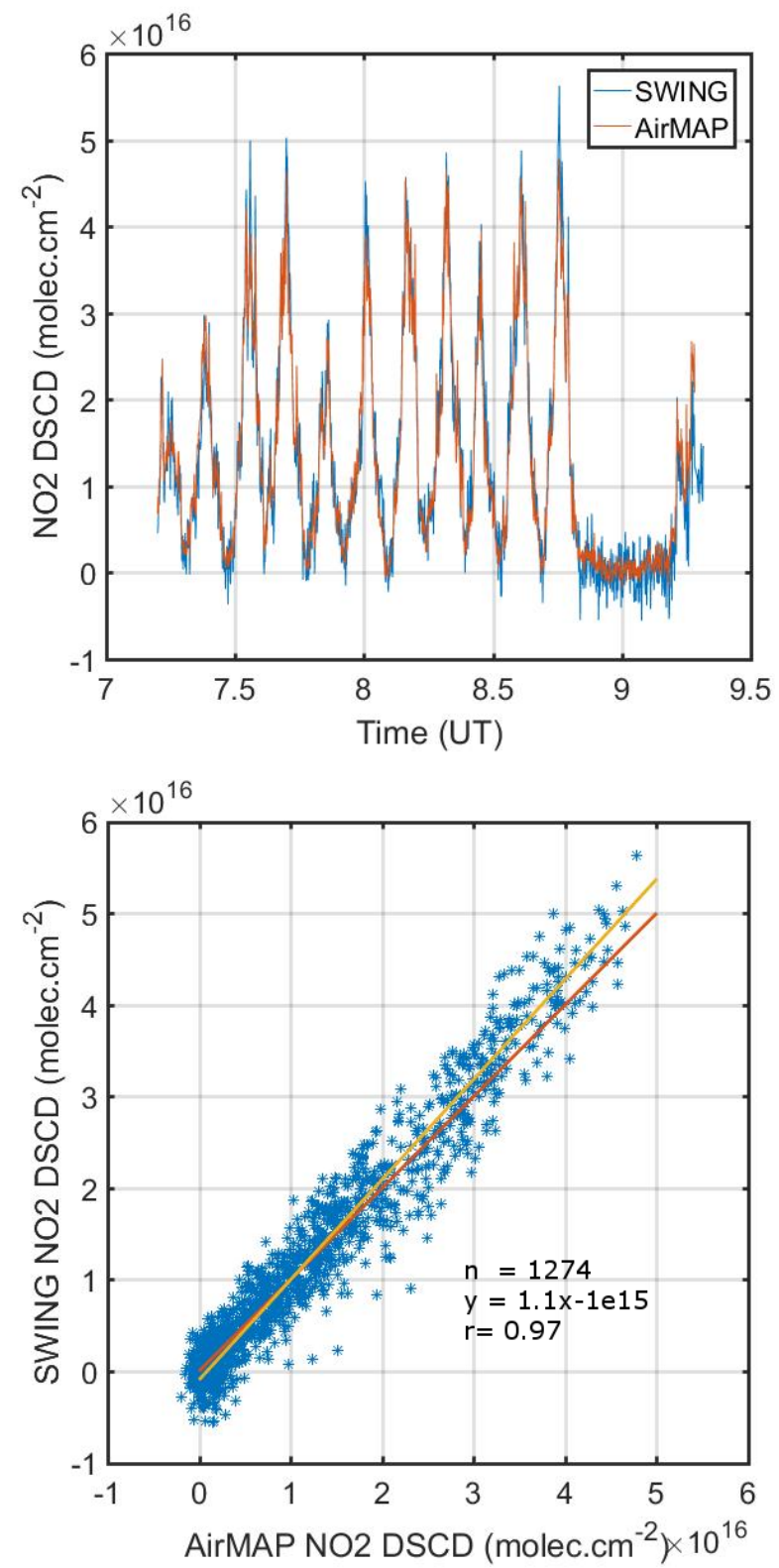

Figure S3. Comparison of the AirMAP and SWING $\mathrm{NO}_{2}$ DSCDs above Bucharest (31 August 2015). The lower panel also shows the orthogonal regression (yellow) and 1:1 (red) lines. 

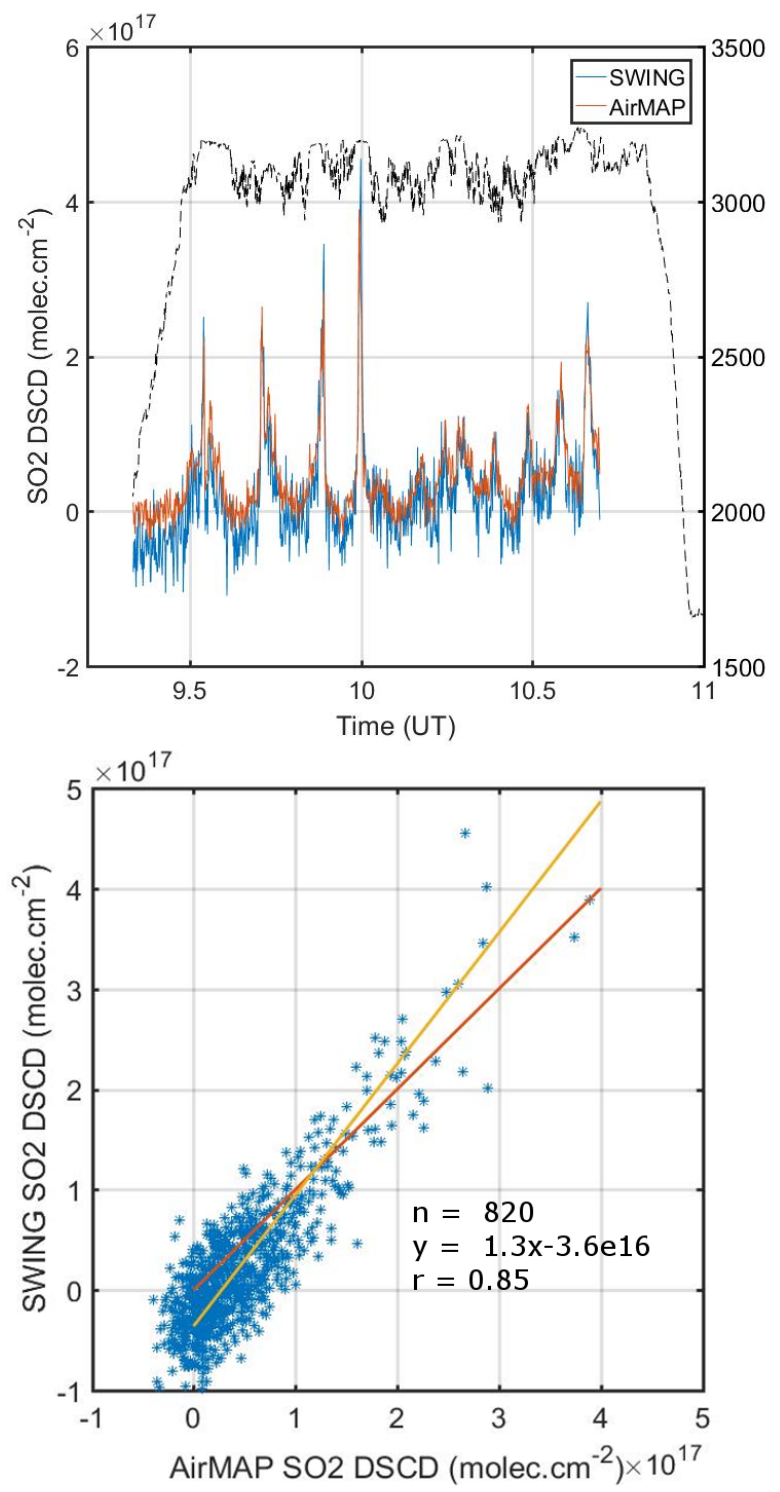

Figure S4. Comparison of the AirMAP and SWING SO 2 DSCDs above the Jiu Valley (28 August 2015). The upper panel also shows the flight altitude. The lower panel shows the orthogonal regression (yellow) and 1:1 (red) lines. 

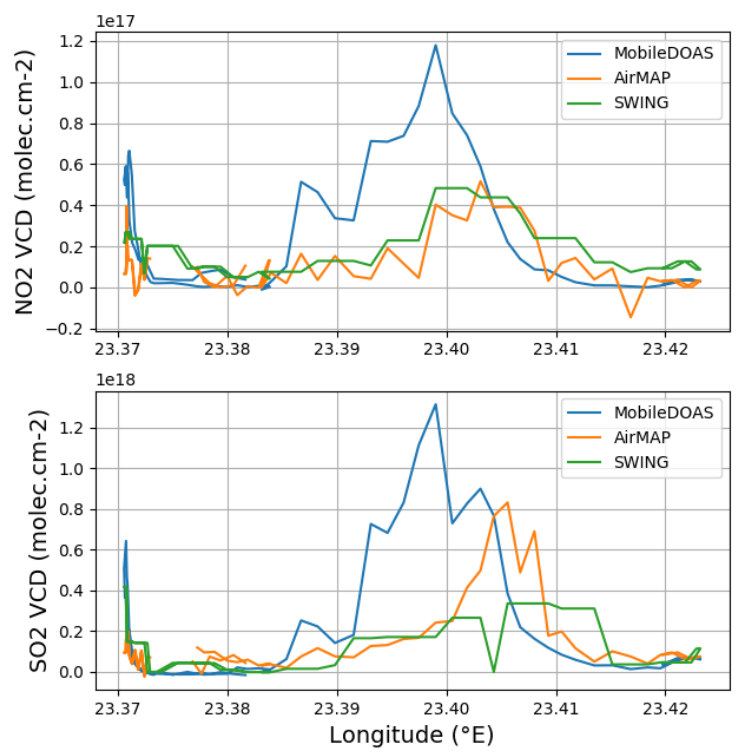

Figure S5. Comparison of the AirMAP, SWING, and UGAL Mobile-DOAS $\mathrm{SO}_{2}$ and $\mathrm{NO}_{2}$ VCDs around Turceni (28 August 2015). Both airborne and ground-based data were recorded between 09:54 and 10:17 UTC.
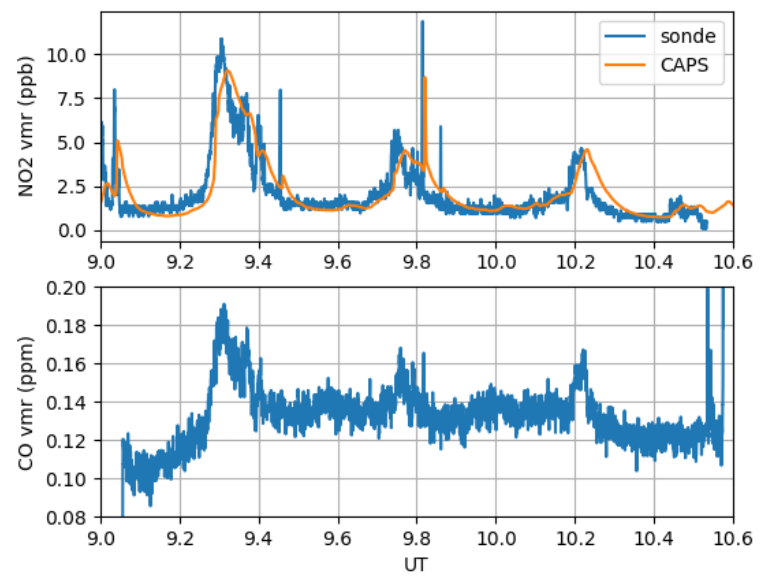

Figure S6. CAPS (orange) and $\mathrm{NO}_{2}$ sonde (blue) measurements (upper panel) with $\mathrm{CO}$ measurements from the PICARRO (lower panel) onboard the BN-2 around Bucharest (25 August 2015). Note that the longer response time of the CAPS explains its time shift compared to the sonde. 


\section{Geophysical findings}

\subsection{Aerosol optical properties and boundary layer height in Bucharest}

Figure S7 shows the lidar extinction profiles at $532 \mathrm{~nm}$ measured at INOE in Margurele $\left(44.35^{\circ} \mathrm{N}, 26.03^{\circ} \mathrm{E}\right)$ during two days of AROMAT-2: 30 (red), and 31 (blue) August 2015. We retrieved these daytime extinction profiles from the backscatter profiles using a column-averaged lidar ratio constrained with the AOD from collocated sunphotometer measurements. The extinction was larger on 30 August 2015. It reached $0.21 \mathrm{~km}^{-1}$ in the boundary layer and up to $0.32 \mathrm{~km}^{-1}$ in an elevated layer at $2 \mathrm{~km}$ altitude. A similar elevated layer also appeared in the FUBISS data (Meier et al., 2017, Fig.7).

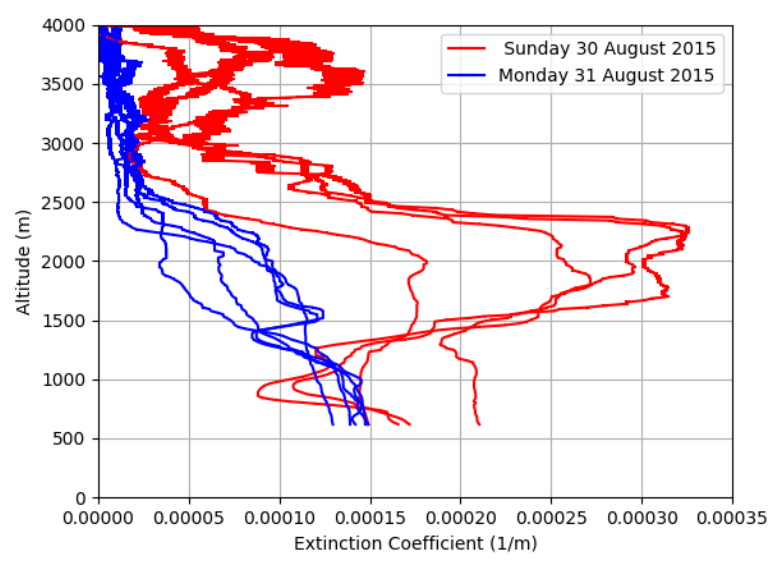

Figure S7. RALI extinction profiles at $532 \mathrm{~nm}$ above Magurele during two days of AROMAT-2. The different lines correspond to the different lidar measurements between 07:33 and 12:32 UTC (30 August 2015) and 07:29 and 15:01 UTC (31 August 2015).

During AROMAT-2, the AOD at $532 \mathrm{~nm}$ was around 0.2 most of the days, except on 30 August 2015 (0.35) and 1 September 2015 (0.05). Interestingly, the maximum AOD was seen on a Sunday, when the anthropogenic emissions of $\mathrm{NO}_{\mathrm{x}}$ from Bucharest were minimal.

We estimated the boundary layer height $(\mathrm{BLH})$ using a gradient method applied to the lidar range corrected signal (Belegante et al., 2014; Timofte et al., 2015). Figure S8 presents such BLH estimates using the RALI lidar observations during AROMAT2 in Bucharest. The BLH varied between $700 \mathrm{~m}$ (morning of the 30 August 2015) and $2500 \mathrm{~m}$ (afternoon of the 24, 26, and 31 August 2015). During AROMAT-1, similar estimates resulted in BLH ranging between $1300 \mathrm{~m}$ (2 September 2014$)$ and 2200 m (11 September 2014). 


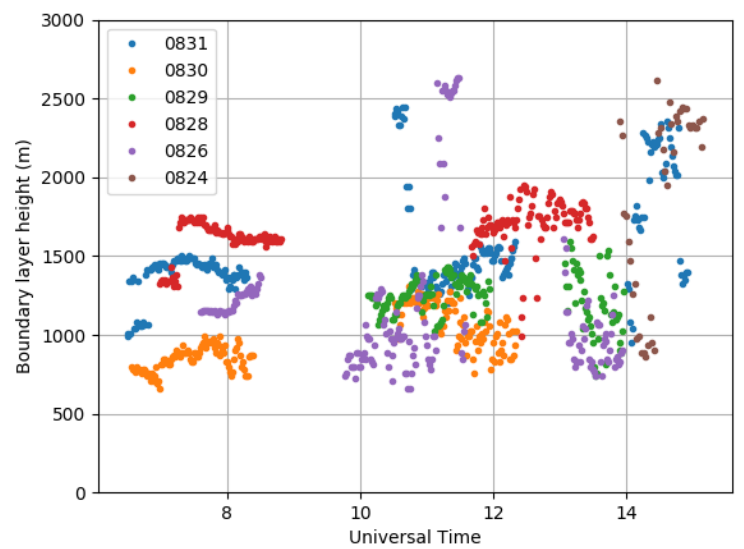

Figure S8. Lidar-derived boundary layer heights above Magurele in August 2015 during AROMAT-2.

\subsection{Power plant plumes in the Jiu Valley}

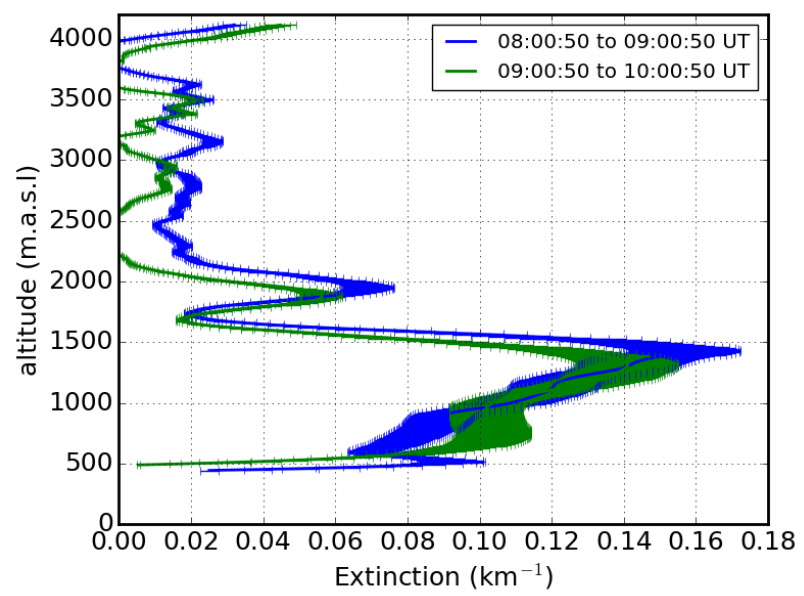

Figure S9. Extinction profiles measured in Turceni by the MILI lidar during the Cessna overpass on 28 August 2015 . Note that the low values around $500 \mathrm{~m}$ are caused by the lidar partial overlap. 


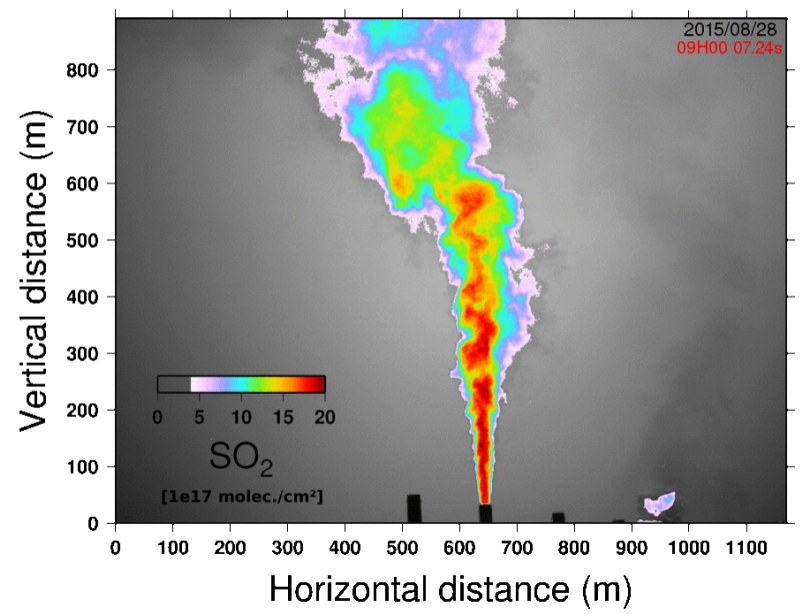

Figure S10. Image of the $\mathrm{SO}_{2}$ plume above the Turceni power plant, recorded with the Envicam2 $\mathrm{SO}_{2}$ camera (28 August 2015). 

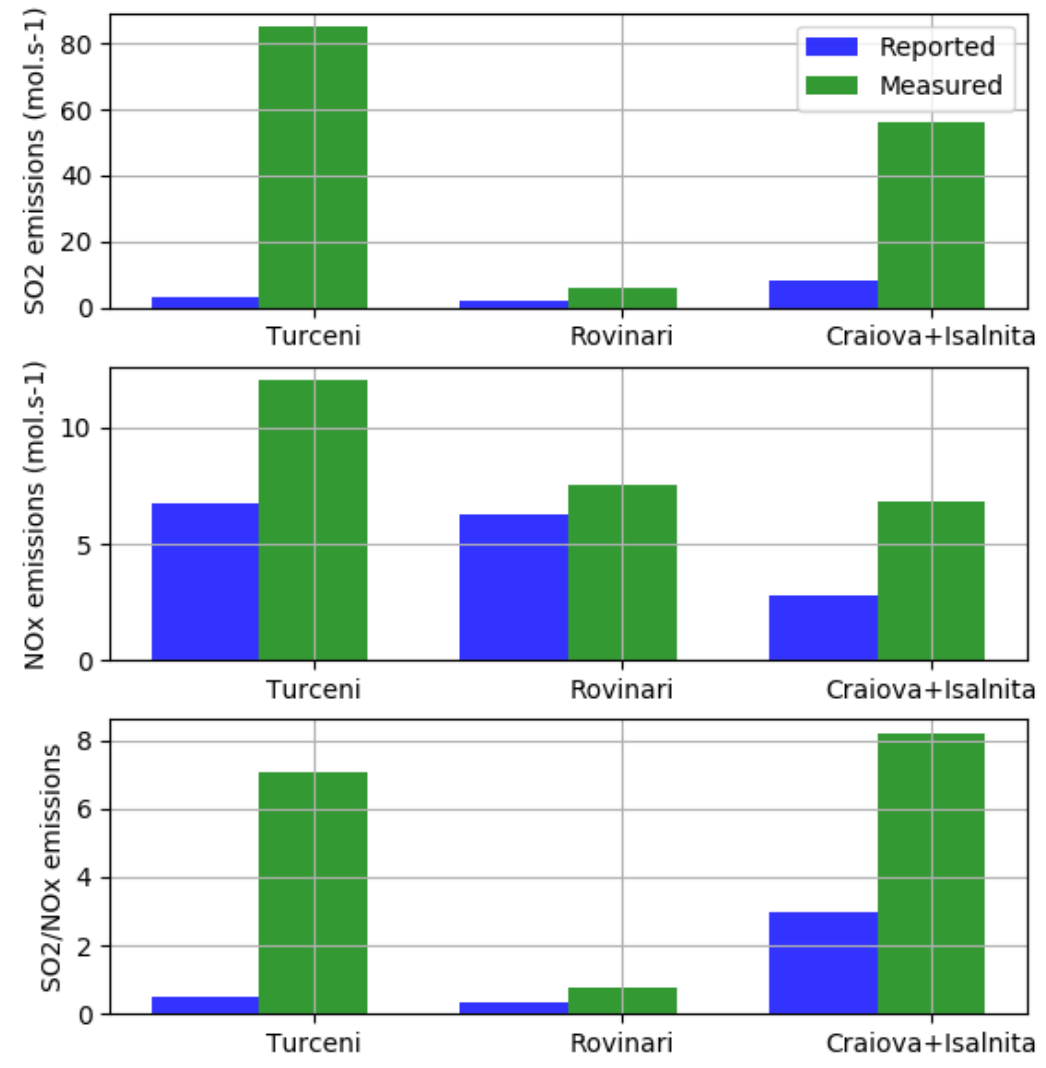

Figure S11. $\mathrm{SO}_{2}$ and $\mathrm{NO}_{\mathrm{x}}$ fluxes from the power plants of the Jiu Valley as (1) measured with the ULM-DOAS measurements on 25 August 2015 (green bars) and (2) estimated from the reported emissions of 2015 assuming constant emissions (blue bars). Uncertainties on the ULM-DOAS fluxes are around $60 \%$. 
Belegante, L., Talianu, C., Nemuc, C., and Nicolae, D.: Detection of local weather events from multiwavelength lidar measurements during the EARLI09 campaign, Rom. J. Phys., 56, 484-494, 2011.

Belegante, L., Nicolae, D., Nemuc, A., Talianu, C., and Derognat, C.: Retrieval of the boundary layer height from active and passive remote sensors. Comparison with a NWP model, Acta Geophysica, 62, 276-289, https://doi.org/10.2478/s11600-013-0167-4, 2014.

Chen, H., Karion, A., Rella, C. W., Winderlich, J., Gerbig, C., Filges, A., Newberger, T., Sweeney, C., and Tans, P. P.: Accurate measurements of carbon monoxide in humid air using the cavity ring-down spectroscopy (CRDS) technique, Atmos. Meas. Tech., 6, 1031-1040, https://doi.org/10.5194/amt-6-1031-2013, 2013.

Constantin, D., Merlaud, A., Van Roozendael, M., Voiculescu, M., Fayt, C., Hendrick, F., Pinardi, G., and Georgescu, L.: Measurements of Tropospheric NO2 in Romania Using a Zenith-Sky Mobile DOAS System and Comparisons with Satellite Observations, Sensors, 13, 3922-3940, https://doi.org/10.3390/s130303922, 2013.

Constantin, D., Merlaud, A., and the AROMAT team: AROMAT-II Final report, Noordwijk, the Netherlands, 2016.

Constantin, D.-E., Merlaud, A., Voiculescu, M., Dragomir, C., Georgescu, L., Hendrick, F., Pinardi, G., and Van Roozendael, M.: Mobile DOAS Observations of Tropospheric NO2 Using an UltraLight Trike and Flux Calculation, Atmosphere, 8, 78, https://doi.org/10.3390/atmos8040078, 2017.

Dekemper, E., Vanhamel, J., Van Opstal, B., and Fussen, D.: The AOTF-based NO2 camera, Atmos. Meas. Tech., 9, 6025-6034, https://doi.org/10.5194/amt-9-6025-2016, 2016.

Kebabian, P. L., Herndon, S. C., and Freedman, A.: Detection of nitrogen dioxide by cavity attenuated phase shift spectroscopy, Anal. Chem., 77, 724-728, https://doi.org/10.1021/ac048715y, 2005.

Kern, C., Lübcke, P., Bobrowski, N., Campion, R., Mori, T., Smekens, J.-F., Stebel, K., Tamburello, G., Burton, M., Platt, U., and Prata, F.: Intercomparison of SO2 camera systems for imaging volcanic gas plumes, J. Volcanol. Geotherm. Res., 300, 22 - 36, https://doi.org/https://doi.org/10.1016/j.jvolgeores.2014.08.026, 2015.

Meier, A. C.: Measurements of horizontal trace gas distributions using airborne imaging differential optical absorption spectroscopy, Ph.D. thesis, University of Bremen, 2018.

Meier, A. C., Schönhardt, A., Bösch, T., Richter, A., Seyler, A., Ruhtz, T., Constantin, D.-E., Shaiganfar, R., Wagner, T., Merlaud, A., Van Roozendael, M., Belegante, L., Nicolae, D., Georgescu, L., and Burrows, J. P.: High-resolution airborne imaging DOAS measurements of $\mathrm{NO}_{2}$ above Bucharest during AROMAT, Atmos. Meas. Tech., 10, 1831-1857, https://doi.org/10.5194/amt-10-1831-2017, 2017.

Merlaud, A.: Development and use of compact instruments for tropospheric investigations based on optical spectroscopy from mobile platforms, Presses univ. de Louvain, 2013.

Merlaud, A., Den Hoed, M., and the AROMAT team: AROMAT Final report, Noordwijk, the Netherlands, 2016.

Merlaud, A., Tack, F., Constantin, D., Georgescu, L., Maes, J., Fayt, C., Mingireanu, F., Schuettemeyer, D., Meier, A. C., Schönardt, A., Ruhtz, T., Bellegante, L., Nicolae, D., Den Hoed, M., Allaart, M., and Van Roozendael, M.: The Small Whiskbroom Imager for atmospheric compositioN monitorinG (SWING) and its operations from an unmanned aerial vehicle (UAV) during the AROMAT campaign, Atmos. Meas. Tech., 11, 551-567, https://doi.org/10.5194/amt-11-551-2018, 2018.

Nicolae, D., Vasilescu, J., Carstea, E., Stebel, K., and Prata, F.: Romanian Atmospheric research 3D Observatory: Synergy of instruments, Rom. Rep. Phys., 62, 2010.

Nicolae, D., Vasilescu, J., Talianu, C., Binietoglou, I., Nicolae, V., Andrei, S., and Antonescu, B.: A neural network aerosol-typing algorithm based on lidar data, Atmos. Chem. Phys., 18, 14 511-14 537, https://doi.org/10.5194/acp-18-14511-2018, 2018.

Schönhardt, A., Altube, P., Gerilowski, K., Krautwurst, S., Hartmann, J., Meier, A. C., Richter, A., and Burrows, J. P.: A wide field-of-view imaging DOAS instrument for two-dimensional trace gas mapping from aircraft, Atmos. Meas. Tech., 8, 5113-5131, https://doi.org/10.5194/amt-8-5113-2015, 2015.

Sluis, W. W., Allaart, M. A. F., Piters, A. J. M., and Gast, L. F. L.: The development of a nitrogen dioxide sonde, Atmos. Meas. Tech., 3, 1753-1762, https://doi.org/10.5194/amt-3-1753-2010, 2010.

Timofte, A., Belegante, L., Cazacu, M. M., B., A., C., T., and S., G.: Study of planetary boundary layer height from LIDAR measurements and ALARO model, J. Optoelectron. Adv. M., 17, 2015.

200 Wagner, T., Ibrahim, O., Shaiganfar, R., and Platt, U.: Mobile MAX-DOAS observations of tropospheric trace gases, Atmos. Meas. Tech., 3, 129-140, 2010.

Zieger, P., Ruhtz, T., Preusker, R., and Fischer, J.: Dual-aureole and sun spectrometer system for airborne measurements of aerosol optical properties., Applied Optics, 46, 8542-8552, 2007. 